\title{
Is the Pandemic Leading to a Paradigm Shift in Higher Education?
}

\author{
Carmen Z. Lamagna and Manzur H. Khan
}

\section{Introduction}

Indoor gatherings of many people are high-risk sites for the spread of COVID-19; this includes schools, colleges and university campuses. This evolving situation will not only be vastly disruptive but will also lead to a paradigm shift in higher education institutions (HEI).

It is not only a daunting challenge for institutions and students alike but even more so for those who are yet to be able to adapt to the change and adopt the 'new normal'. That in itself is an incredibly difficult task for those in developing countries, given their pre-existing conditions of socio-economic constraints, slow advancement of IT infrastructure, and the poor literacy and the general apathy towards technology. Amidst this global crisis, HEIs have been stripped to their fundamental functionalities and put to an eccentric acid test.

The pandemic is an unpredictable and unforeseen event with extreme consequences that is prompting us to rethink how we operate HEIs at every level. No doubt, this disruption has caused a major and likely unequal interruption in student learning and assessment in all educational institutions.

Students live in close community proximity, they take classes in enclosed classrooms, eat and spend time for classwork and activities in communal settings, and cheer on their teams and engage socially with the usual physical contact like shaking hands, high fives and hugs. With the shutdown, some HEIs have moved quickly to create a remote-teaching alternative.

The pandemic could be a catalyst for online education and other ed-tech tools, with physical distancing being the most effective tool for flattening the infection curve in

C. Z. Lamagna $(\bowtie) \cdot$ M. H. Khan

American International University-Bangladesh, Dhaka, Bangladesh

e-mail: clamagna@aiub.edu

M. H. Khan

e-mail:manzur@aiub.edu

(C) The Author(s) 2021 
the absence of test capacity, and of a vaccine. In this context, sending students home and finishing the academic year/semester online is an appropriate solution. Physical distancing is a temporary new norm, prompting HEIs to develop pedagogical and administrative practices to enable operations from a distance.

Unfortunately, in Bangladesh, most HEIs struggle to pursue activities from a distance as they are not built for remote work and may have little experience in carrying it out or managing it, unlike the tech sector.

There is also a financial backlash as the shift to online delivery and adding the requisite support proves to be costly. Students may not be in the classroom, but they are getting the same curriculum and courses by distance-a shift that requires tremendous efforts from teachers and administrative staff and supported by digital means.

Amidst all these factors, Bangladesh has been brought to a standstill by the pandemic. All the hustle-bustle of a densely populated country has come to a quiescent halt; the only sound to be heard is the whisper of anxiety. The struggle of HEIs to react to this sudden catastrophe has been magnified by uncertainties. According to a survey, out of 151 universities (public and private), 63 universities (2 public and 61 private) reportedly started online classes during this pandemic (Mohiuddin 2020). Despite this report, there are doubts about the success of remote teaching carried out by these universities, with the exception of a successful few, which are mostly private universities.

Classes have been shifted online, enabling students and teachers to conduct and undertake their teaching within the safety of their homes with a unified communication and collaboration platform that combines persistent workplace chat, video meetings, file storage, and application integration. With a dynamic interface and diverse features, students and faculties can now participate in a unique teachinglearning experience, that not only ensures the health and welfare of both, but also encourages the continuity of academic activities in these difficult times. Teachers are delivering lectures through video conferencing while students can communicate with them through video, audio or message boards for queries, and class participation.

Online platforms enable an interactive and versatile set-up as an alternate medium to conventional in-class teaching and learning environments, augmenting another layer of advanced digitized education in the modern world today. The initiative has safeguarded students from incurring the loss of the semester.

\section{Will Students Have Discovered Online Education as a Viable and More Affordable Alternative?}

The question is whether this temporary experience of distance learning represents a more affordable and viable alternative for students? Online education alleviates housing costs by letting students take advantage of their current living situation, thereby saving expenses each semester. Textbooks are another expensive reality of tradi- 
tional HE that online education alleviates. Thanks to the digital nature of eLearning, many of the course materials are included in the curriculum. The underlying technology that makes all this possible, the internet, laptops and smartphones is something which students can actually afford. Transportation costs can also be considerably reduced. Parking fees, tolls, fuel, and the wear-and-tear of everyday driving can add up significantly. When it comes to HE, not everything should be analyzed in terms of financial value and cost-saving; there is the more important aspect of whether students can receive a truly valuable education. The internet currently holds the most extensive collection of academic material; it has essentially become what Ptolemy envisioned when he founded the Ancient Library of Alexandria thousands of years ago. The most prestigious lecturers in the world have agreed to be digitally filmed and recorded for the benefit of the entire world; when students go online, it does not necessarily mean they are receiving less of an education with fewer costs.

\section{Unified Theory of Acceptance and Use of Technology (UTAUT2)}

Based on the Unified Theory of Acceptance and Use of Technology (UTAUT2) model (Venkatesh et al. 2012), a questionnaire was developed to determine student acceptance of online classes, and Entrepreneurial Potential Model (Moghavvemi et al. 2012) was integrated to study how the COVID-19 pandemic situation moderated their ultimate use behaviour.

This integrated model focused on the challenges of this paradigm shift-in terms of stakeholders' behavioural intention, availability of the online platform, prior experience, attitude towards usage (ease of use and usefulness) and most importantly the effect of coronavirus on the behavioural intention to ultimately adopting online classes. Additionally, the issues of social and cultural impact were also taken into consideration.

An online survey was conducted at the end of the spring 2019-20 semester. The survey population consisted of randomly chosen students from private universities which represents the major HEI student share.

\section{Results and Discussions}

The study hypotheses based on the research integrated framework (UTAUT2 and Entrepreneurial Potential Model) were analyzed and tested using Statistical Package for the Social Sciences (SPSS). The prime objective of the study was whether the constructs of the research framework influence the behavioural intention (Islam et al. 2013) of the students to adopt online classes and whether this pandemic ultimately 
moderated their decision. The following results were observed (organized as per the constructs used in the study):

- Performance Expectancy (PE): The extent of a student's belief that online classes will be advantageous. (Venkatesh et al. 2012). Performance expectancy has a significant effect on the behavioural intention of students to attend online classes.

- Effort Expectancy (EE): The ease of using technology during online classes (Jambulingam 2013). Effort expectancy has a significant effect on the behavioural intention of students to attend online classes.

- Social Influence (SI): The extent of influence of those people who are important to the students in accepting the online classes (Venkatesh et al. 2012). Social influence has a significant effect on the behavioural intention of students to attend online classes.

- Facilitating Conditions (FC): The assessment of organizational and technical infrastructure to support the online classes (Venkatesh et al. 2003). Facilitating conditions have a significant effect on the behavioural intention of students to attend online classes.

- Hedonic Motivation (HM): The enjoyable and fulfilling experience of using the technology of online classes (Brown and Venkatesh 2003). Hedonic motivation has a significant effect on the behavioural intention of students to attend online classes.

- Value (V): The assessment of the resources spent on, and perceived value gained from attending online classes (Venkatesh et al. 2003). Value has a significant effect on the behavioural intention of students to attend online classes.

- Precipitating Events (PEV): Effect of sudden change in environment caused by COVID-19 pandemic on the perception of student's decision to accept this radical change in their everyday campus life and completely shift to online classes. It captures the effect of external factors on student's intention to act and is considered as a moderator on the connection between their intention and behaviour to adopt online classes (Krueger et al. 2000). Schindehutte et al. (2000) categorized such moderating triggers into five key dimensions: opportunity- driven vs. threat-driven, market pull vs. technology push, internal vs. external (to organization), top-down vs. bottom-up, systematic or deliberate search vs. chance or opportunism (Schindehutte et al. 2000; Moghavvemi and Mohd Salleh 2011). In this study, the authors posit how environmental, external factors and unforeseen events can change the student's intention. Precipitating Event moderated the behavioural intention of students to attend online classes.

The data further suggested that hedonic motivation has the highest effect whereas facilitating condition has the lowest effect on the students' behavioural intention to adopt online learning. It was also found that precipitating events (sudden crisis caused by COVID-19) affected and moderated their behavioural intention to adopt online learning.

Some of the important and interesting demographic observations are-the highest percentage of the students $(37 \%)$ who responded to the survey came from families 
with a monthly income range of 400-600 USD; the highest percentage of respondents (40\%) uses the internet for 3-5 h daily. Even though the majority of students indicated their first preference of using the internet is for education, but most of them $(37 \%)$ spend $3-5 \mathrm{~h}$ on social media, very interestingly $48 \%$ (highest) female students are in this same bracket. In metropolitan cities, the majority of their internet connectivity is via broadband; but in rural areas, most of them depend on mobile data.

\section{Conclusion}

Agility, flexibility, and resiliency are not just fundamental skills for the 21st century students. They are imperative for the 21 st century educational institutionsespecially in an era when disruptive pathogens and natural calamities are predicted to become all the more common.

Whether or not COVID 19 quickly subsides, the life as we knew it had been permanently altered. Tumultuous times have a way of reordering reality and, in the process, opening doors to new opportunities and mindsets (Lamagna 2020).

In alignment with UTAUT2's postulates, it was found that student acceptance of online classes was influenced by its advantages, its user-friendly technologically, social influence on students, support from university and technology providers, its enjoyable experience, cost-benefit assessment. Most importantly, the sudden change in their lifestyle caused by COVID-19 pandemic significantly affected their decision to engage into online classes and hence, is one of the prominent attributes of this paradigm shift in the higher education institutions.

This study was based on students who successfully participated in an online class in a homogenous environment. Unfortunately, that might not have been the case for many universities of the country, even the ones who managed to take classes online during this coronavirus pandemic. Hence, it may not be possible to generalize the findings for the HEIs of Bangladesh. Even though the most widely popular research framework was used to assess the adoption of technology, the nature of the situation was also undoubtedly unprecedented. This fact also establishes the novelty of this article.

It certainly opens a whole new frontier for the nation's higher education policymakers, educators and administrators. Along with motivated HEI leaders, technology can transform the curriculum and better prepare students for the new world of work, helping students to unleash their potential and harness their talents. Digital transformation of institutions will provide equality, accessibility, and empowerment for all to what they can make and do. 


\section{References}

Brown, S. A., \& Venkatesh, V. (2003). Bringing Non-Adopters Along: The Challenge Facing the PC Industry. Communications of the ACM (46:4), 76-80.

Islam, M. Z., Kim, P. C. L., \& Hassan, I. (2013). Intention to use advanced mobile phone services (AMPS). Management Decision, 51(4), 824-838.

Jambulingam, M. (2013). Behavioral intention to adopt mobile technology among tertiary students. World Applied Sciences Journal, 22(9), 1262- 1271.

Krueger, N., Reilly, M.D. \& Carsurud, A.L. (2000). Competing models of entrepreneurial intention. Journal of Business Venturing, Vol. 15 Nos. 5/6, pp. 411-432.

Lamagna, C. Z. (2020). A PARADIGM SHIFT: The Case of AIUB. The Daily Star. Retrieved from: www.thedailystar.net/shout/news/paradigm-shift-the-case-aiub-1891033 (16.06.2020)

Moghavvemi, S. \& Mohd Salleh, N. A. (2011). Entrepreneurs Intention toward IT-Innovation Adoption in Malaysia. Journal of Communications of Global Information Technology (COGIT). (3) $78-86$.

Moghavvemi, S.; Mohd Salleh, N.A.; Zhao, W. \& Mattila, M.M. (2012). The Entrepreneur's Perception of Information Technology Adoption: An Empirical Analysis of the Role of Precipitating Events on Usage Behavior. Innovation: Management, Policy \& Practice. 14(3)' 220-235.

Mohiuddin Alamgir (2020). Online Classes Amid Shutdown: A distant reality, still for many, The Daily Star, Retrieved from: www.thedailystar.net/frontpage/news/online-classes-amidshutdown-distant-reality-still-many-1900918 (16.06.2020)

Schindehutte, M.; Morris, M.H. \& Kuratko, D.F. (2000). Triggering Events, Corporate Entrepreneurship and the Marketing Function. Journal of Marketing Theory and Practice. 8(2), 18-30.

Venkatesh, V., Thong, J.Y.L. \& Xu, X. (2012). Consumer acceptance and use of information technology: extending the unified theory of acceptance and use of technology. MIS Quarterly, 36(1), 157-178.

Venkatesh, V.; Morris, M.G.; Davis, G.B. \& Davis, F.D. (2003). User Acceptance of Information Technology: Toward a Unified View. MIS Quarterly. 27(3), 425-478.

Carmen Z. Lamagna is the Vice-Chancellor of the American International University-Bangladesh (AIUB). Under her guidance from its inception in 1995, the university has earned distinction as a source of quality education. The university grew from 70 to more than 11,000 students across the Faculties of Science and Technology, Engineering, Business Administration and Arts \& Social Sciences.

Manzur H. Khan is currently working as the Director of Student Affairs and also as the Associate Professor of Computer Science in the American International University-Bangladesh (AIUB). He has closely observed the growth of AIUB as an administrator and a faculty member over the last 17 years from around 3000 to 10000 students currently enrolled in AIUB. He is also a member of the Academic Council and the Syndicate of AIUB.

Open Access This chapter is licensed under the terms of the Creative Commons Attribution 4.0 International License (http://creativecommons.org/licenses/by/4.0/), which permits use, sharing, adaptation, distribution and reproduction in any medium or format, as long as you give appropriate credit to the original author(s) and the source, provide a link to the Creative Commons license and indicate if changes were made.

The images or other third party material in this chapter are included in the chapter's Creative Commons license, unless indicated otherwise in a credit line to the material. If material is not included in the chapter's Creative Commons license and your intended use is not permitted by statutory regulation or exceeds the permitted use, you will need to obtain permission directly from the copyright holder.

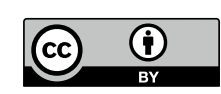

